\title{
Towards modelling realistic ageing rates of amorphous silicon devices in operational environment
}

Jiang Zhu*, Martin Bliss, Thomas R. Betts, and Ralph Gottschalg

Centre for Renewable Energy Systems Technology (CREST), School of Electrical, Electronic and Systems Engineering, Loughborough University, Leicestershire, LE11 3TU, U.K.

E-mail: J.Zhu@lboro.ac.uk

This paper presents a method to de-convolute the annealing and degradation processes of amorphous silicon devices. This will allow modelling realistic outdoor operation. Six devices underwent 14000 hours indoor light exposure at different and varying thermal conditions. The devices are exposed to light at variable temperatures between $25^{\circ} \mathrm{C}$ and $85^{\circ} \mathrm{C}$ under illumination as well as annealed in the dark. The temperature set-points were altered several times during the test to gain insights on how the balance between light induced degradation and thermal annealing is shifted. Measurements show that the degradation level is largely determined by the device's operating temperature and both processes balance themselves out without consideration of device history. This is explained by the proposed modelling approach based on the defect pool model. The key parameters in the proposed modelling approach are the effective activation energies for degradation and annealing. 


\section{Introduction}

The degradation rates of outdoor a-Si modules reported in the literature are normally between $0.5 \%$ and $2.5 \%$ per year ${ }^{1)}$ and vary according to location ${ }^{2)}$. The site-specific degradation can currently not be predicted. This paper delivers a key element towards such a model. The variation in degradation can be attributed to many factors such as module manufacturer, manufacturing year, operating time, operating condition and potentially operating history. ${ }^{3-11)}$ These factors are correlated and their effects cannot easily be separated. There are, however, strong indications that the specific operating environment plays a significant role in the absolute amount of ageing experienced by different technologies. ${ }^{12-16)}$ Ruther et al. ${ }^{17,18)}$ exposed a number of similar modules at different locations with different climates and observed variable ageing. They suggested temperature to determine the degradation rate of modules, rather than absolute irradiance as modules stabilised at different levels after changing locations. Similar findings were reported for indoor constant condition of lightsoaking and annealing tests that the a-Si module efficiency saturated in dependence of light intensity and temperature. ${ }^{19,20}$ Typically, a rapid degradation of a-Si modules is observed during initial light soaking, ${ }^{21)}$ which is followed by a much slower degradation as also experienced by other devices during operation. This is typically described as a stretched exponential function. ${ }^{22,23)}$ Heating up modules will result in increased efficiencies, i.e. annealing of the device. The degradation was described by rate equations for the number of defects. ${ }^{24,25)}$ A model to link the balance of these competing effects is required to describe outdoor operation and potentially calculate device properties of e.g. a-Si top level devices in something like a silicon based tandem device.

The key contribution of this paper is to model realistic ageing and annealing at module level in dependence of environmental stresses and device operating history. The modelling approach is based on the theory of 'defects pool', ${ }^{26)}$ which allows the defects to be created independently of energy of the incident light. The developed ageing and annealing functions are thermal activated and characterised by the effective activation energies, which represent the defect distributions. The model provides insights into the distribution of the defect density and the shift of the activation energy which describes the temperature effects on degradation and annealing.

In order to characterise the environmental stresses, the environmental 'dose' is defined. ${ }^{27)}$ Thus device ageing can be evaluated on a unique basis which enables a comparative study of degradation at different ageing conditions.

\section{Indoor Stress Testing}




\subsection{Stress chamber and stress profile}

Six single junction a-Si mini-modules have been aged and annealed in a light and temperature stress chamber. The chamber can accommodate mini-modules of size of up to $10 \mathrm{x} 10 \mathrm{~cm}$. It uses metal halide lamps with Class C spectrum, which generate an irradiance of 500W/m². The homogeneity of light intensity for different position is within $\pm 3.3 \%$ (Class $B$ ). The temperature of each device is controlled separately, which means that devices can be kept at different temperatures. Fig 1 shows the chamber used in this work.

In this study, the mini-modules were initially kept at $25^{\circ} \mathrm{C}, 50^{\circ} \mathrm{C}$ and $85^{\circ} \mathrm{C}$ with two devices at each temperature. This covers a good proportion of temperature conditions of devices during illuminated outdoor operation. During the test, the temperature set-points were altered for some devices in order to study the response to the changes in the operating temperature. After 8500 hours of light soaking, all devices were annealed in the dark for another 5500 hours. The details and duration of the temperature profile and light soaking setup in four stages of the test are shown in Fig 2. During the light soaking part of the test, all devices were loaded at maximum power point as modules normally operate outdoors.

\subsection{Measurements}

During this experiment, device I-V curve, light intensity and temperature at the back surface of modules were measured in situ. The measurements were taken at 10 minute intervals, with devices set to maximum power point during light soaking. Devices are measured at non-STC condition and under different irradiance and temperature levels. Therefore, this paper investigates the relative change of properties rather than absolute values. The relative values of the maximum power $\left(\mathrm{P}_{\mathrm{MPP}}\right)$ output of the test devices over the complete duration of the test are plotted in Fig 3 after being corrected to STC.

During stage I of the test (0-3300 hours), devices D1 and D2, which have been operating at $85^{\circ} \mathrm{C}$, showed the smallest degradation of $25-28 \%$ in power, while D5 and D6 (operating at $25^{\circ} \mathrm{C}$ ) showed the largest degradation of 64-67\%. All devices started to stabilise after around 3000 hours, 500 hours before the alteration of temperature profiles in stage II. The dependence on temperature is very clear in the banding of the results. This allows the conclusion that the balance between degradation and annealing is predominantly determined by the operating temperature rather than specific material parameters. This theorem was tested by mixing the operating temperatures in stage II.

During stage II (3300-8500 hours), the temperature set-points of D3 $\left(50^{\circ} \mathrm{C}\right)$ and $\mathrm{D} 5\left(25^{\circ} \mathrm{C}\right)$ were changed to $85^{\circ} \mathrm{C}$. A rapid recovery of power was seen for both devices during the first 200 hours. At 
this point, the power of the devices was recovered to a similar level to that of D1, which was operating at $85^{\circ} \mathrm{C}$ since the start of test. After the initial 200 hours all the three devices experienced a similar rate of ageing at $1.5-2 \%$ over the next 2000 hours. The operating temperatures of D2 $\left(85^{\circ} \mathrm{C}\right)$ and $\mathrm{D} 4\left(50^{\circ} \mathrm{C}\right)$ were changed to $25^{\circ} \mathrm{C}$. Both devices responded quickly and their operational performance matched that of D6, the device constantly being operated at $25^{\circ} \mathrm{C}$. Overall the banding of all devices operated at different temperatures but identical irradiance stresses is very clear. This allows the conclusion that the temperature is key in determining the overall balance of ageing and annealing. Devices have not stabilised fully despite being annealed for several thousand hours at $85^{\circ} \mathrm{C}$.

There is a discontinuity in Figure 3 after 6200 hours. This is due to the lamps being replaced and the spectrum changed. The mismatch between monitoring diode and a-Si devices has changed and thus the light levels changed.

In the stage III (8500-11000 hours), all devices were annealed in the dark. Test device D1 and D2, annealed at $85^{\circ} \mathrm{C}$, showed faster power recovery than the other devices annealed at lower temperatures. Furthermore, after 400 hours of annealing the maximum power of D2 recovered to the same level as D1 even though device D2 had degraded nearly twice as much before the start of stage III.

During stage IV of the test (11000-14000 hours), all six devices were annealed in dark at a temperature of $85^{\circ} \mathrm{C}$. The maximum power output of all devices recovered to roughly the same level no matter what conditions the devices had been exposed to. However, the time scale shows that even when no stress is applied (i.e. in the dark), annealing may be a slow process.

In conclusion, the device state seems to be dependent predominantly on operating temperature (in equilibrium) and not so much of operational history. Changes between one state to another reasonably fast but annealing may continue at slower rates for considerable amounts of time. This leads to the hypothesis that there are two independent processes with temperature dependent reaction kinetics. This is the basis of the model being developed in the following section.

\section{Model Development}

\subsection{Distribution of Defects}

The defects pool model describes the number of dangling-bonds in the material that can take a range of energies due to the disorder of amorphous network. The defects can be created in different charge states at different energy levels between valence band and conduction band. ${ }^{26)}$ Fig 4 shows a typical density of states for good quality a-Si devices (demonstration only). ${ }^{28)}$ 
The density of states indicates the maximum number of possible defects that can be created at different energies, which is temperature-independent. ${ }^{25)}$ The defect occupancy (shaded area in Fig 4) at specific energy level, however, depends on temperature and experienced stresses. ${ }^{29)}$ Furthermore, the creation of new defects is inhibited by existing defects as the available sites for new defects decrease. These self-limiting features are extremely useful for modelling the temperature effect on ageing and annealing.

\subsection{Rate Equations and Dose Model}

The degradation of a-Si devices is related to the light-induced changes in photoconductivity and is typically characterised by the increase in the defect density $N$. This defect density exhibits a semiempirical relationship with the power degradation in a-Si devices ${ }^{30,31)}$ as shown in Eq. (1):

$$
\frac{\Delta P}{P_{0}}=A \log \left(1+\frac{N}{N_{0}}\right)
$$

where $\Delta P$ is the degradation in device maximum power, $P_{0}$ is the initial device maximum power, $N_{0}$ is the initial defect density and $A$ is a constant.

The kinetic rate equations for defects creation and annealing used in this work are given in Eq. (2)$(4){ }^{25)}$

$$
\begin{aligned}
& \frac{d N}{d t}=N_{c}-N_{a} \\
& \frac{d N_{c}}{d t}=B e^{-\frac{E_{a d}}{k_{B} T}\left(\frac{G}{N}\right)^{2}} \\
& \frac{d N_{a}}{d t}=C e^{-\frac{E_{a a}}{k_{B} T}}\left(N-N_{0}\right)
\end{aligned}
$$

where $N_{c}$ is the defects created, $N_{a}$ is the defects annealed, $T$ is the device temperature and $G$ is the light intensity. $E_{a d}$ and $E_{a a}$ are activation energies to characterise the light degradation and thermal annealing. Eq. (2) shows that the degradation and annealing processes work against each other.

With the empirical relationship between $P$ and $N$, two dose models were developed. One is for ageing that is dominated by the light-induced degradation (stage I for all devices and stage II for D2 and D4), and the other is for ageing dominated by the thermal activated annealing (beginning of stage II for D3 and D5, stages III and IV for all devices). 
Taking into account the maximum number of possible defects and linking the power degradation with the levels of temperature and irradiance, the dose model for light-induced degradation dominated ageing is developed as:

$$
\Delta P / P_{0} \propto \operatorname{dose}\left(N=G^{2 / 3} e^{\frac{E_{a 1}}{k_{B} T}}\right)
$$

where $E_{a 1}=E_{a a}-E_{a d}$, is the activation energy representing the combined rates for defects annealing and formation. As the defects are created over a range of energies, the $E_{a 1}$ in reality should be a function of energy over the same range. However, in order to simplify the dose model, a single value is assigned to $E_{a 1}$ in Eq. (5) which can be considered as an effective activation energy. The effective activation energy is not a simple average, but takes the shape of the distribution into account. Normally, it can be calculated by comparing ageing rates at different temperatures. ${ }^{25)}$ Analysing the device D1, D3, D6 power degradations at different temperatures in stage I, the $E_{a 1}$ is calculated and equals $0.48 \mathrm{eV}$. Then the dose can be calculated based on Eq. (5) and Fig 5 plots the normalised $P_{M P P}$ of D1, D3, D6 in stage I against the calculated dose. All devices follow the same degradation curve as indicated by the dashed line before they stabilised.

When annealing dominates the device behaviour, only Eq. (4) is taken into account, the dose model for thermal activated annealing is developed as:

$$
\Delta P / P_{0} \propto \operatorname{dose}\left(N-N_{0}=e^{\frac{-E_{a 2}}{k_{B} T}}\right)
$$

where $E_{a 2}$ is effective activation energy for annealing.

Analysing the annealing rates at different temperatures without light for device D2, D4, D6 in Stage III, the $E_{a 2}$ is calculated and equals $1.15 \mathrm{eV}$. Then the dose can be calculated and plotted in Fig 6 . The maximum power is normalised to the value at the beginning of annealing for each device. All annealing behaviours follow a same annealing curve as indicated by the dashed line.

\subsection{Shift of the Effective Activation Energy}

It has been shown that after a low-temperature annealing, most of the remaining dangling bonds have high activation energies. ${ }^{25)}$ The result of this work is similar. Comparing the annealing rates of D2 in Stage III, D4 and D6 in Stage IV at the same temperature of $85^{\circ} \mathrm{C}$, different effective activation energies are obtained: $1.15 \mathrm{eV}$ for $\mathrm{D} 2,1.27 \mathrm{eV}$ for $\mathrm{D} 4$ and $1.2 \mathrm{eV}$ for $\mathrm{D} 6$. This change is due to D4 and D6 having experienced a preceding annealing at $50^{\circ} \mathrm{C}$ and $25^{\circ} \mathrm{C}$, respectively. Thus some defects with lower activation energies have been annealed, which leads to a shift of the effective activation energy towards higher levels as illustrated in Fig 7. The shaded areas represent the defect density at the beginning of stage III for D2, stage IV for D4 and D6. 


\section{Conclusions}

The power degradation for six a-Si devices degraded in long-term 14000 hours are presented and discussed in this paper. The aim is to develop models for the outdoor performance and thus to understand ageing and annealing behaviour. The conditions were varied during the ageing to let irradiance being carried out at different temperatures. These changes resulted in very pronounced banding of the devices, i.e. within a short time all devices found equilibrium at similar performance levels. This indicates that the operational history may not be as important for a-Si devices as assumed by many concerned with real life performance. The ageing as well as annealing can be modelled as competing processes, both showing an Arrhenius like dependency. The annealing at realistic operating conditions (i.e. $\max 85^{\circ} \mathrm{C}$ ) takes a long time and thus only the incremental part of the annealing should be considered when developing long-term performance models. One will need to have rate equations for both, annealing and degradation, processes and these in dependence of irradiance and temperature. It is shown here that the Arrhenius approximation delivers excellent results.

\section{Acknowledgment}

This work has been supported by a joint UK-India initiative in solar energy through a joint project 'Stability and Performance of Photovoltaics (STAPP)' funded by the Research Councils UK (RCUK) Energy Programme (contract no: EP/H040331/1) and by the Department of Science and Technology (DST) in India. 


\section{References}

1) D. C. Jordan, S. R. Kurtz, Prog. Photovolt: Res. Appl. 21, 12 (2011).

2) D. Wu, J. Zhu, T. R. Betts, R. Gottschalg, Tech. Dig. 21st Int. Photovol. Science and Engineering Conf., Fukuoka, 2011.

3) T. Ishii, T. Takashima, K. Otani, Prog. Photovolt: Res. Appl. 19, 170 (2011).

4) C.R. Osterwald, J. Adelstein, J.A. del Cueto, B. Kroposki, D. Trudell, T. Moriarty, Proc. 4th IEEE World Conf. on Photovol. Energy Conversion, Hawaii, 2006, p. 2085.

5) B. Raghuraman, V. Laksman, J. Kuitche, W. Shisler, G. Tamizhani, H. Kappor, Proc. 4th IEEE World Conf. on Photovol. Energy Conversion, Hawaii, 2006, p. 2214.

6) H. Haeberlin, P. Schaerf, Proc. 25th European Photovol. Sol. Energy Conf./5th World Conf. on Photovol. Energy Conversion, Valencia, 2010, p. 4756.

7) K. Akhmad, H. Okamoto, F. Yamamoto, A. Kitamura, Jpn. J. Appl. Phys. 36, 629 (1997).

8) Y. Nakata, A. Yokota, H. Sannomiya, S. Moriuchi, Y. Inoue, K. Nomoto, M. Itoh, T. Tsuji, Jpn. J. Appl. Phys. 31, 168 (1992).

9) R. Gottschalg, C.N. Jardine, R. Ruther, T.R. Betts, G.J. Conibeer, J. Close, D.G. Infield, M.J. Kearney, K.H. Lam, K. Lane, H. Pang, R. Tscharner, Proc. 29th IEEE Photovol. Spec. Conf., 2002, p.1699.

10) K. Astawa, T.R. Betts, R. Gottschalg, Sol. Energy Mater. Sol. Cells 95, 119 (2011).

11) R. Gottschalg, T.R. Betts, A. Eeles, S.R. Williams, J. Zhu, Sol. Energy Mater. Sol. Cells 119, 169 (2013).

12) M. Isomura, N. Hata, S. Wagner, Jpn. J. Appl. Phys. 31, 3500 (1992).

13) G. Kleiss, A. Raicu, K. Bucher, Proc. 23rd IEEE Photovol. Spec. Conf., 1993, p. 896.

14) T. Yanagisawa, T. Kojima, T. Koyanagi, K. Takahisa, K. Nakamura, Sol. Energy Mater. Sol. Cells 69, 287 (2001).

15) C. P. Lund, K. Luczak, T. Pryor, J. C. L Cornish, P. J. Jennings, P. Knipe, F. Ahjum, Renew. Energy 22, 287 (2001).

16) J. A. del Cueto and B. von Roedern, Prog. Photovolt: Res. Appl. 7, 101 (1999).

17) R. Rüther, G. Tamizh-Mani, J. del Cueto, J. Adelstein, A. Montenegro, B. von Roedern, Proc. 3rd World Conf. on Photovol. Energy Conversion, 2003, p. 501.

18) R. Rüther, J. del Cueto, G. Tamizh-Mani, A. Montenegro, S. Rummel, A. Anderberg, B. von Roedern, Proc. 33rd IEEE Photovol. Spec. Conf., San Diego, 2008, p. 1.

19) K. Takahisa, T. Kojima, K. Nakamura, T. Koyanagi, T. Yanagisawa, Sol. Energy Mater. Sol. Cells 49, 179 (1997).

20) W. Luft, B. van Roedem, B. Stafford, L. Mrig, Proc. 23rd IEEE Photovol. Spec. Conf., 1993, p. 860. 
21) D. L. Staebler and C. R. Wronski, Appl. Phys. Lett. 31, 292 (1977).

22) D. Redfield, R. H. Bube, Appl. Phys. Lett. 54, 1037 (1989).

23) R. S. Crandall, Phys. Rev. B 43, 4057 (1991).

24) M. Stutzmann, W.B. Jackson, C.C. Tsai, Appl. Phys. Lett. 45, 1075 (1984).

25) M. Stutzmann, W.B. Jackson, C.C. Tsai, Phys. Rev. B 32, 23 (1985).

26) Y. Bar-Yam, J. D. Joannopoulos, Theories of defects in amorphous semiconductors, J. NonCryst. Solids 97-98, 467 (1987).

27) J. Zhu, M. Bliss, T. R. Betts, R. Gottschalg, Proc. 21st Int. Photovol. Science and Engineering Conf., Fukuoka, 2011.

28) R. Street, Technology and Applications of Amorphous Silicon (Springer, New York, 2000), p. 4.

29) M. J. Powell, S. C. Deane, Phys. Rev. B 48, 815 (1993).

30) L. Yang, L. Chen, Appl. Phys. Lett. 63, 3 (1993).

31) Z. E. Smith, S. Wagner, B. W. Faughnan, Appl. Phys. Lett. 46, 1078 (1985). 

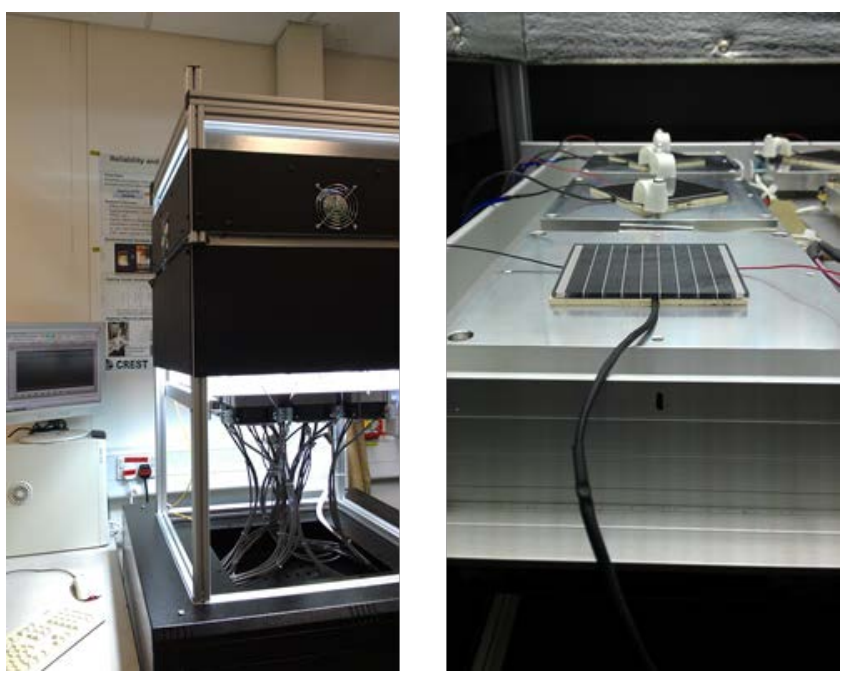

Fig. 1 Light and temperature stress chamber. It uses metal halide lamps, has separate temperature controller for each device and can control the module loading conditions.

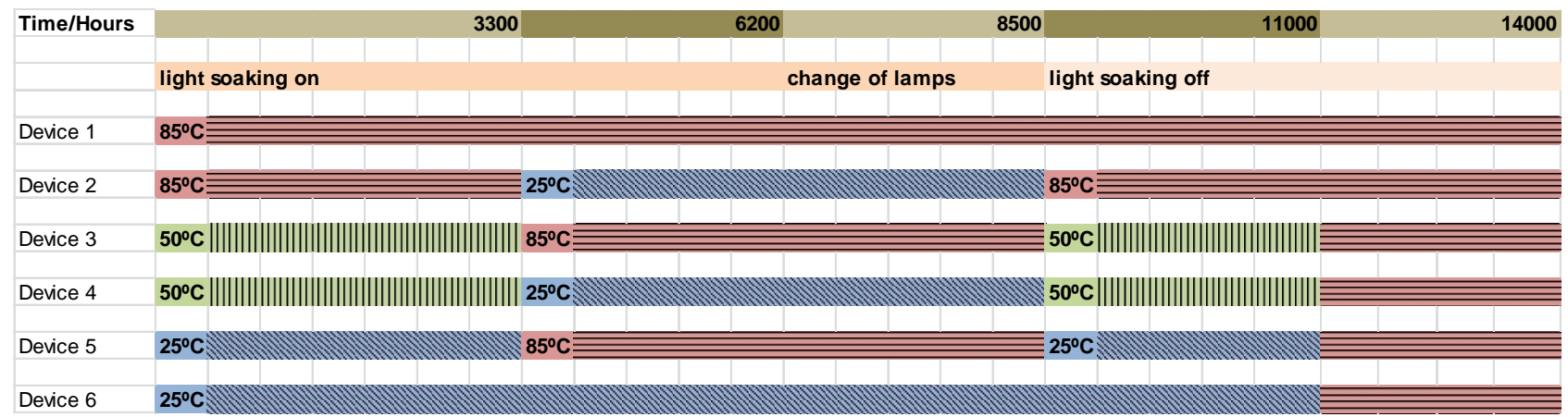

Fig. 2 Indoor stress test aging conditions with temperature set-points and light soaking setup; same colours represent same temperature set-point.

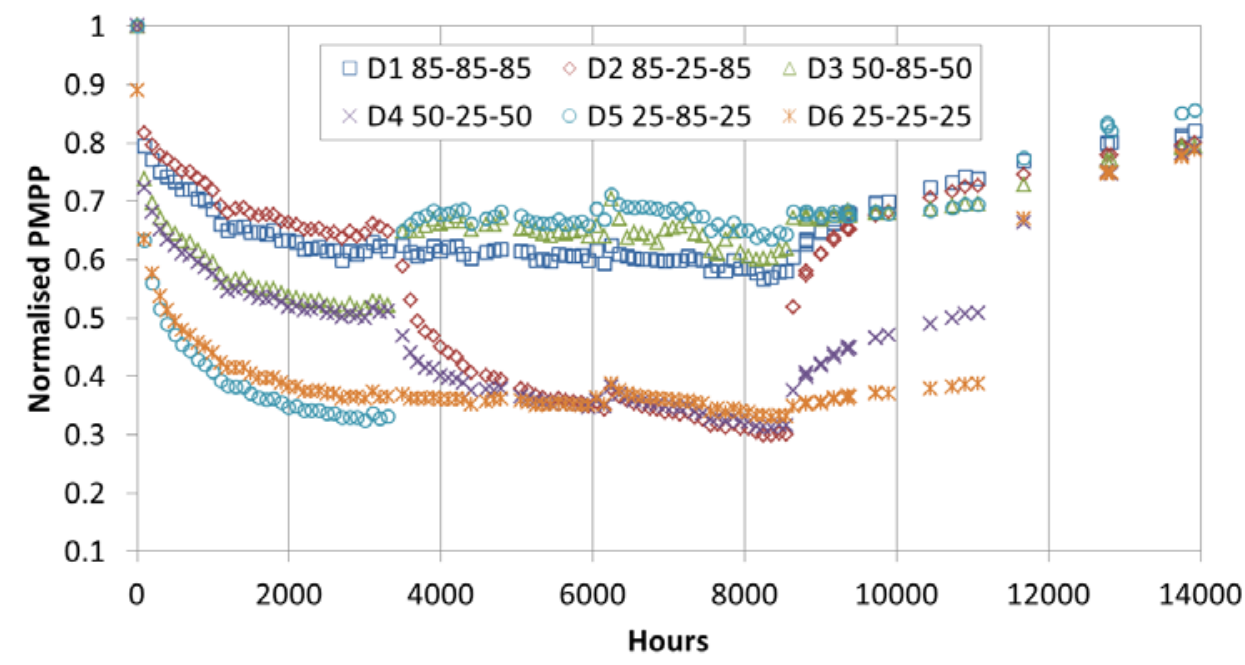

Fig. 3 Maximum power $\left(\mathrm{P}_{\mathrm{MPP}}\right)$ output of the test devices over the 14000 hours stress test; irradiance and temperature correction has been applied for comparability. (Not all data points are plotted) 


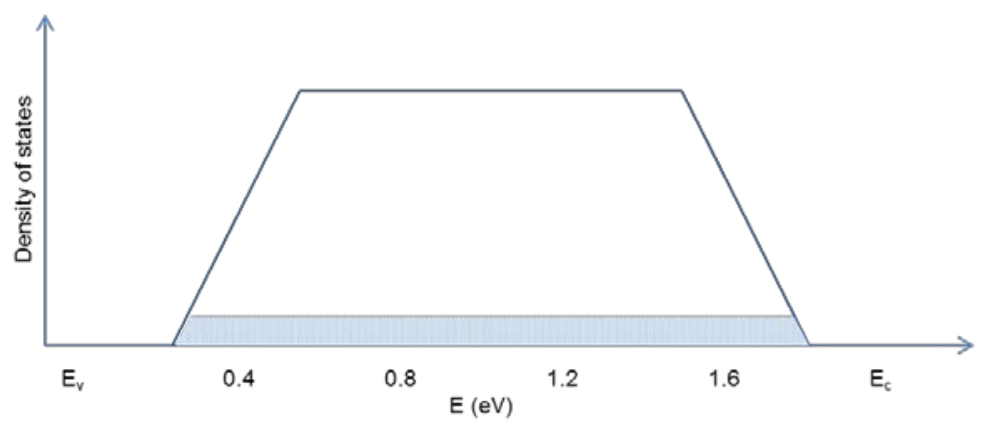

Fig. 4 Density of states for possible dangling-bond in a-Si (solid line) and sites occupied by defects (shaded area).

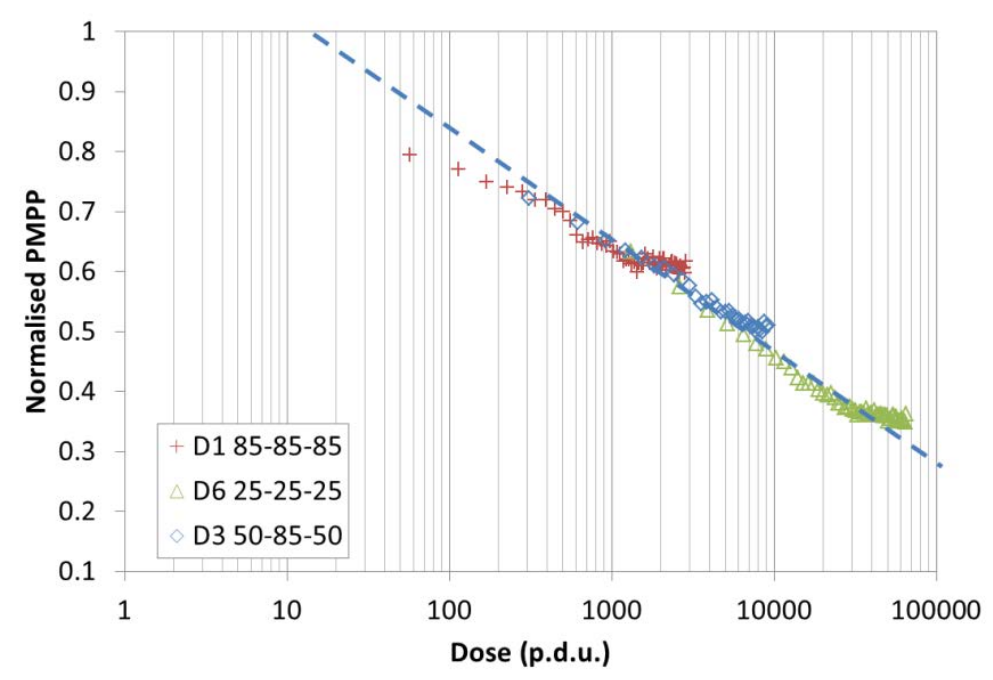

Fig. 5 Normalised $\mathrm{P}_{\mathrm{MPP}}$ of D1, D3 and D6 against dose during stage I.

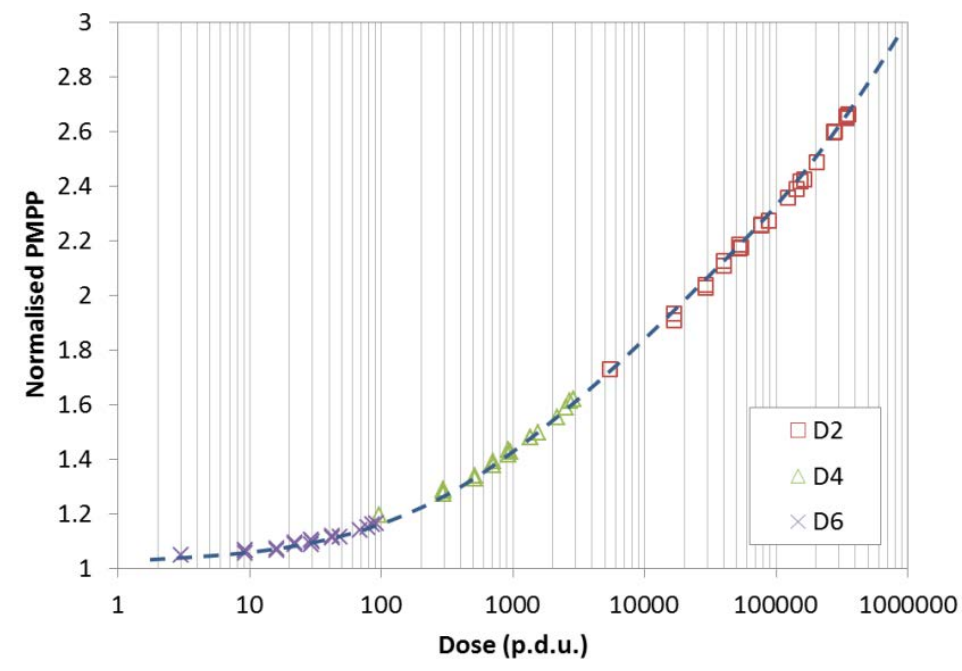

Fig. 6 Normalised $\mathrm{P}_{\text {MPP }}$ (relative values to the start of annealing) of D2, D4 and D6 against dose during stage III. 


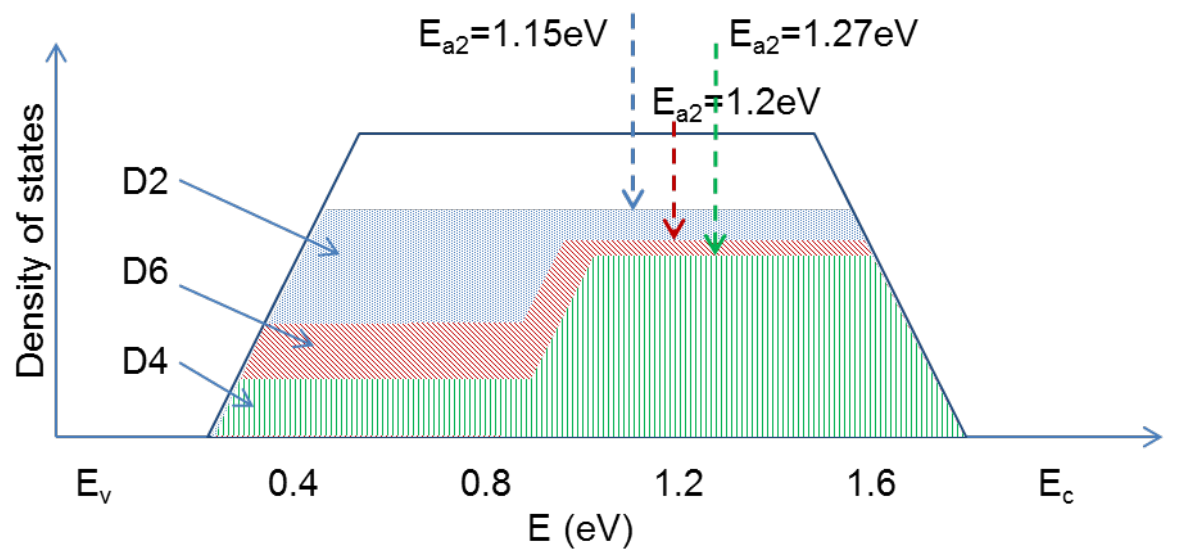

Fig. 7 Illustration of the shift of effective activation energy due to a preceding annealing at low temperature. 